\title{
Upregulation of Gastric Norepinephrine With $\beta$-Adrenoceptors and Gastric Dysmotility in a Rat Model of Functional Dyspepsia
}

\author{
Jin SONG ${ }^{1,2}$, Tianyuan WANG ${ }^{1}$, Xiaoli $\mathrm{ZHANG}^{3}$, Bo $\mathrm{LI}^{1,2}$, Chunyang $\mathrm{ZHU}^{2}$, Shengsheng \\ ZHANG $^{2}$
}

${ }^{1}$ Beijing Institute of Traditional Chinese Medicine, Beijing, China, ${ }^{2}$ Beijing Hospital of Traditional Chinese Medicine, Capital Medical University, Beijing, China, ${ }^{3}$ Department of Physiology and Pathophysiology, School of Basic Medical Science, Capital Medical University, Beijing, China

Received March 22, 2019

Accepted November 20, 2019

Epub Ahead of Print December 19, 2019

\begin{abstract}
Summary
Disordered motility is one of the most important pathogenic characteristics of functional dyspepsia (FD), although the underlying mechanisms remain unclear. Since the sympathetic system is important to the regulation of gastrointestinal motility, the present study aimed to investigate the role of norepinephrine (NE) and adrenoceptors in disordered gastric motility in a rat model with FD. The effect of exogenous NE on gastric motility in control and FD rats was measured through an organ bath study. The expression and distribution of $\beta$-adrenoceptors were examined by real-time PCR, Western blotting and immunofluorescence. The results showed that endogenous gastric NE was elevated in FD rats, and hyperreactivity of gastric smooth muscle to NE and delayed gastric emptying were observed in the rat model of FD. The mRNA levels of $\beta_{1}$-adrenoceptor and norepinephrine transporter (NET) and the protein levels of $\beta_{2}$-adrenoceptor and NET were increased significantly in the gastric corpus of FD rats. All three subtypes of $\beta$-adrenoceptors were abundantly distributed in the gastric corpus of rats. In conclusion, the enhanced NE and $\beta$-adrenoceptors and NETs may be contributed to the disordered gastric motility in FD rats.
\end{abstract}

\section{Key words}

Functional dyspepsia - Disordered gastric motility • Norepinephrine $\bullet \beta$-adrenoceptors

\section{Corresponding author}

S. Zhang, Department of Gastroenterology, Beijing Hospital of Traditional Chinese Medicine, Capital Medical University, No. 23
Meishuguanhoujie, Dongcheng district, 100010 Beijing, China. E-mail: zhss2000@163.com

\section{Introduction}

Dyspepsia comprises a constellation of symptoms referable to the gastroduodenal region of the upper gastrointestinal tract (Talley et al. 2015). According to a recent internet-based cross-sectional health survey of adults in the USA, Canada and the UK, approximately $10 \%$ of the adult population fulfills symptom-based criteria for Rome IV functional dyspepsia (FD) (Aziz et al. 2018). FD is not a lifethreatening disease but often reduces patients' quality of life and is associated with high societal costs (Lacy et al. 2013, Talley et al. 1995). Elucidating the pathogenesis of FD would be conducive to searching for new therapeutic targets and reducing the burden on society. Although not fully understood, several mechanisms have been considered to be involved in the pathogenesis of FD: disordered motility, visceral hypersensitivity and mucosal alterations (Tack et al. 2018). Disordered motility is one of the most important mechanisms because delayed gastric emptying occurs in up to one-third of FD patients (Carbone et al. 2014, Stanghellini et al. 2014). However, the underlying mechanism of disordered motility in FD patients remains debatable.

The enteric nervous system (ENS), which is linked to the central nervous system (CNS) mediated by the autonomic nervous system (ANS), regulates the 
motility and secretory functions of the GI tract. FD has been described as a multifactorial disease that involves the ENS and the CNS (Sahan et al. 2018). It has been reported that FD patients manifest an imbalance of ANS function and vulnerability to recovery from external stimuli (Tominaga et al. 2016). Automatic dysfunction, including that of the sympathetic and parasympathetic system, has been observed in patients with FD (Park et al. 2001). Norepinephrine (NE) is the main neurotransmitter in the sympathetic nervous system and is widely involved in many physiological and pathological functions, including gastrointestinal motility. Enhanced sympathetic nerve activity and elevated plasma NE have been reported to be related to gastric hypersensitivity in a rat model of FD (Winston et al. 2016). However, there are no published studies describing the association between the sympathetic nervous system and disordered motility in FD.

The aim of the present study was to identify the role of the noradrenergic system (including neurotransmitters and receptors) in disordered gastric motility in a rat model of FD by means of gastric emptying study, ex vivo motility recording, enzyme-linked immunesorbent assay (ELISA), real-time reverse transcriptionpolymerase chain reaction, Western blotting and immunofluorescence. This study helps elucidate the mechanism underlying FD-associated gastric dysmotility.

\section{Materials and Methods}

Animals

Adult male Sprague-Dawley rats weighing 200-220 g were used in all experiments. The rats were housed in an animal facility with $12 \mathrm{~h}$ light and dark cycles and free access to food and water. All procedures were carried out according to the ethics and animal welfare regulation requirements approved by the Institutional Animal Care and Use Committee (Beijing Institute of Traditional Chinese Medicine).

The procedure for creating FD model rats has been described previously (Chang et al. 2017). A sponge clamp was used to clinch the distal end of the rats' tail, and the strength was enough to induce pain without skin damage. FD model rats received 7 days of clamp stimulation 3 times a day for $30 \mathrm{~min}$ each time. To avoid infection due to a scuffle injury, the injured area was rubbed with $0.5 \%$ iodine at the end of stimulation. After one week, the FD model rats showed symptoms such as irritability, reduced consumption and weight growth, and loose stools.

\section{Gastric emptying}

Before the experiment, each rat in the control and FD groups was kept separately in a single cage and fasted for $24 \mathrm{~h}$ while having free access to water. Then, each rat was free to eat preweighed pellets for $1 \mathrm{~h}$ until the food was removed again. Two hours later, each rat was sacrificed by an overdose of anesthetics, the pylorus and cardia were ligated, and then the stomach was carefully excised. The contents of the stomach were removed, dried and weighed. The percentage of gastric emptying was calculated according to the following formula:

Gastric emptying $\%=(1-$ weight of residue in the stomach/weight of food intake) $\times 100 \%$

\section{Recording of contractile activity through an organ bath \\ Rats in the control and FD groups were} sacrificed by an overdose of anesthetics, and the stomach was removed and placed in Krebs-Henseleit solution (K-HS, composition: $\mathrm{NaCl}, 118.4 \mathrm{mM}$; KCl, $4.7 \mathrm{mM}$; $\mathrm{MgSO}_{4} \cdot 7 \mathrm{H}_{2} \mathrm{O}, 1.2 \mathrm{mM}$; $\mathrm{KH}_{2} \mathrm{PO}_{4}, 1.2 \mathrm{mM}$; $\mathrm{NaHCO}_{3}$, $25 \mathrm{mM}$; glucose, $11 \mathrm{mM}$; and $\mathrm{CaCl}_{2}, 2.5 \mathrm{mM}, \mathrm{pH} 7.4$, all chemicals were purchased from Beijing Chemical Works) maintained at $37^{\circ} \mathrm{C}$ and bubbled with $95 \%$ $\mathrm{O}_{2} / 5 \% \mathrm{CO}_{2}$. The luminal contents were gently flushed out, and smooth muscle strips (approximately 9-11 mm in length and 1-2 $\mathrm{mm}$ in width) were cut along the direction of the longitudinal smooth muscle. The strips were mounted vertically under an initial tension of $1 \mathrm{mN}$ in an organ bath containing $20 \mathrm{ml}$ of oxygenated $\left(95 \% \mathrm{O}_{2}\right.$ and $5 \% \mathrm{CO}_{2}$ ) K-HS at $37^{\circ} \mathrm{C}$ and equilibrated for $1 \mathrm{~h}$. Tension changes in the muscle preparation were recorded isometrically through a force transducer (MLT0201/ RAD; AD Instruments, Barcelona, Spain). The mechanical activity was digitized using a bridge amplifier (ML228; AD Instruments, Bella Vista, Australia), and tracings were visualized and analyzed by using LabChart 7 software (AD Instruments). The motility index (MI) was calculated based on the area under the curve $\left(\mathrm{gS}^{-3}\right)$ before and after NE administration.

\section{Measurement of NE by ELISA}

Rats in the control and FD groups were sacrificed by an overdose of anesthetics. The method of tissue preparation has been described previously (Zhang et al. 2015a, Zhang et al. 2015b). The stomachs were quickly removed, cleaned and placed in Krebs-Hensleit solution (K-HS). The antrum and fundus of stomachs were quickly removed and the gastric corpus was pinned 
flat with the muscle side down in a Petri dish containing ice-cold oxygenated K-HS. The mucosa/submucosa layers were carefully removed under a dissecting microscope to obtain the serosa and the muscle preparations. The separated muscularis of gastric corpus was flash-frozen in liquid nitrogen and then homogenated. A commercial ELISA kit (E02N0013, Blue Gene, China) was used to detect the NE content in the muscular layer of the gastric corpus. All reagents were used at room temperature, and the prepared standard and sample were added to the appropriate wells in an antibody precoated microtiter plate. Then, $10 \mu \mathrm{l}$ of balance solution and $50 \mu \mathrm{l}$ of conjugate were added separately to each well. After $1 \mathrm{~h}$ of incubation at $37^{\circ} \mathrm{C}$, the incubation mixture was removed, and the plate was washed manually and automatically (five times each). Two types of substrate ( $10 \mu \mathrm{l}$ of substrate $\mathrm{A}$ and $50 \mu \mathrm{l}$ of substrate B) were added to each well of the plate and incubated for $15 \mathrm{~min}$ at $25^{\circ} \mathrm{C}$ (avoid sunlight). After $50 \mu \mathrm{l}$ of stop solution was added to each well, the optical density (O.D.) at $450 \mathrm{~nm}$ was immediately determined using a microplate reader. A standard curve was constructed based on the O.D. value of each standard, and the concentration of samples corresponding to the mean absorbance was calculated from the standard curve.

\section{Real-time polymerase chain reaction}

Control and FD model rats were sacrificed by an overdose of anesthetics, and the lamina muscularis of the gastric corpus was obtained. Total RNA was extracted by homogenization in an extraction kit (Servicebio, Wuhan, China), and complementary DNAs were synthesized by using a RevertAid First Strand cDNA Synthesis Kit (ThermoFisher, Waltham, MA, USA). The specific primers are listed in Table 1. As mentioned in our previous study, the $\beta_{1^{-}}, \beta_{2^{-}}, \beta_{3^{-}}$-adrenoceptors and NET transcript levels were measured with the FastStart Universal SYBR Green Master kit (Roche, Basel, Switzerland) using a light cycler instrument (ABI, Waltham, USA). Data were analyzed using StepOne ${ }^{\mathrm{TM}}$ Software (Version 2.3, ThermoFisher, Waltham, MA, USA).

Table 1. Sequences of primers.

\begin{tabular}{lccc}
\hline Primers & $\begin{array}{c}\text { GenBank } \\
\text { accession number }\end{array}$ & Primer sequence & $\begin{array}{c}\text { Primer location in } \\
\text { the sequence }\end{array}$ \\
\hline \multirow{2}{*}{ sAPDH } & NM_017008.4 & S: CTGGAGAAACCTGCCAAGTATG & $814-835$ \\
& & A: GGTGGAAGAATGGGAGTTGCT & $931-951$ \\
Adr- $\beta_{1}$ & NM_012701.1 & S: CTCGTCCGTCGTCTCCTTCTA & $681-701$ \\
& & A: CCATGATGATGCCCAGTGTCTT & $937-958$ \\
Adr- $\beta_{2}$ & NM_012492.2 & S: CGACTACAACCGTCACCAACT & $386-407$ \\
& & A: GAAGGGCGATGTGATAGCAAC & $596-616$ \\
Adr- $\beta_{3}$ & NM_013108.2 & S: TTCAACCCGCTCATCTACTGC & $1232-1252$ \\
& & A: CACCTTCATGCCATCAAACCT & $1382-1403$ \\
$N E T$ & SM_031343.1 & A: ACTTTGTCCTCTTTGTGCTCCTG & $854-876$ \\
& & & $950-969$
\end{tabular}

GAPDH, glyceraldehyde-3-phosphate dehydrogenase; Adr, Adrenoceptor; NET, norepinephrine transporter.

\section{Western blotting analysis}

As described in our previous study (Song et al. 2014), the frozen muscular layer of the gastric corpus $(30 \mathrm{mg})$ was homogenized in $300 \mu \mathrm{l}$ of ice cold RIPA lysis buffer (R0010, Solarbio, China) containing fresh protease inhibitor, namely, $1 \%$ phenylmethanesulfonyl fluoride (PMSF, Solarbio, China). The total tissue lysates were sonicated and centrifuged at $12000 \mathrm{rpm}$ for $30 \mathrm{~min}$ at $4{ }^{\circ} \mathrm{C}$, and the cellular debris was removed. After the total protein concentration was determined by a bicinchoninic acid assay (BCA), protein samples $(100 \mu \mathrm{g}$, dissolved in loading buffer with $20 \%$ bromophenol blue) were separated by $10 \%$ sodium dodecyl sulfate polyacrylamide gel electrophoresis $(120 \mathrm{~V}, 80 \mathrm{~mA})$ and transferred onto a polyvinylidene fluoride membrane (Millipore, Billerica, MA, USA) at $0{ }^{\circ} \mathrm{C}$ (295 mA, $\left.90 \mathrm{~min}\right)$. Nonspecific binding sites were blocked in a blocking buffer containing $10 \%$ nonfat milk 
in Tris-buffered saline (TBST, $20 \mathrm{mM}$ Tris-Cl, $\mathrm{pH} 7.5$, containing $0.15 \mathrm{M} \mathrm{NaCl}, 2.7 \mathrm{mM} \mathrm{KCl}$ and $0.05 \%$ Tween 20) for $1 \mathrm{~h}$ at room temperature. The blocked membrane was incubated with the primary antibodies (Table 2) at $4{ }^{\circ} \mathrm{C}$ overnight and then incubated with the appropriate secondary antibodies (Table 2) for $1 \mathrm{~h}$ at room temperature. The membranes were washed 3 times (each for $5 \mathrm{~min}$ ) in TBST, reacted with ECL solution for 1-2 min and then exposed to a film. After the film was developed, the integrated intensity of the bands was analyzed by ImageJ, and the expression levels of $\beta$-actin were used as an internal reference.

Table 2. Antibodies used in this study.

\begin{tabular}{|c|c|c|c|c|}
\hline Antigen & $\begin{array}{c}\text { Immunizing antigen or } \\
\text { conjugation }\end{array}$ & Host species & Dilution & Source/Catalog No. \\
\hline$A d r-\beta_{1}$ & $\begin{array}{l}\text { Immunizing antigen or } \\
\text { conjugation }\end{array}$ & Rabbit & $1: 1000$ & Abcam/ab3442 \\
\hline$A d r-\beta_{2}$ & $\begin{array}{c}\text { Synthetic peptide } \\
\text { corresponding to Mouse } \beta_{1} \text {-AR } \\
\text { aa } 394-408\end{array}$ & Rabbit & $1: 1000$ & Abcam/ab182136 \\
\hline$A d r-\beta_{3}$ & $\begin{array}{l}\text { Syntetic within Human } \beta_{2} \text {-AR } \\
\text { aa } 35 \text { the C-terminus }\end{array}$ & Rabbit & $1: 1000$ & Abcam/ab94506 \\
\hline$N E T$ & $\begin{array}{l}\text { Generated against unique } \\
\text { N-terminal peptide that are } \\
\text { unique to the norsdrenaline } \\
\text { transporter protein }\end{array}$ & Rabbit & $1: 1000$ & Abcam/ab41559 \\
\hline Actin & $\begin{array}{l}\text { KLH conjugated Synthetic } \\
\text { peptide corresponding to } \\
\text { Mouse } \beta \text {-Actin }\end{array}$ & Mouse & $1: 1000$ & Servicebio/GB12001 \\
\hline $\begin{array}{l}\text { Goat anti- } \\
\text { rabbit } \operatorname{Ig} G\end{array}$ & Horseradish peroxidase & Goat & $1: 3000$ & KPL/5220-0336 \\
\hline $\begin{array}{l}\text { Goat anti- } \\
\text { mouse IgG }\end{array}$ & Horseradish peroxidase & Goat & $1: 3000$ & KPL/5220-0341 \\
\hline
\end{tabular}

GAPDH, glyceraldehyde-3-phosphate dehydrogenase; Adr, Adrenoceptor; NET, norepinephrine transporter.

\section{Statistics and data analysis}

Data are presented as the mean \pm SEM. Statistical analyses were performed using a paired or unpaired $t$-test. " $n$ " refers to the number of rats or the number of pairs. A $P<0.05$ was considered statistically significant. Statistics and graphs were performed by Prism, version 6.01 (GraphPad Software, Inc., San Diego, CA, USA).

\section{Results}

NE content and gastric motility in control and $F D$ rats

As shown in Figure 1A, the GE rate of solid food in FD model rats was significantly reduced compared with that in controls $(56.25 \pm 4.16 \%$ vs. $69.75 \pm 2.86 \%, \mathrm{n}=6, P<0.05)$. Because norepinephrine
(NE) is the main neurotransmitter of the sympathetic nervous system (SNS), we measured its content in the gastric corpus by ELISA. The results showed a significantly elevated NE content in the muscular layer of the gastric corpus in FD model rats compared with that in control rats $(38.63 \pm 4.97 \mathrm{ng} / \mathrm{mg}$ vs. $18.26 \pm 2.12 \mathrm{ng} / \mathrm{mg}$, $\mathrm{n}=7, P<0.01$, Fig. 1B). Representative contractile tracings of longitudinal strips of the gastric corpus are shown in Figure 1C. Exogenous NE $(1 \mu \mathrm{M})$ inhibited the contractile activity of the longitudinal strip of gastric corpus in both control and FD model rats. Interestingly, the reduction rate of the motility index induced by NE was higher in the FD model than in control rats ( $84.23 \pm 1.95 \%$ vs. $69.68 \pm 3.39 \%, n=8, P<0.01$, Fig. $1 D)$, reflecting enhanced adrenergic reactivity in the gastric motility of FD rats. 

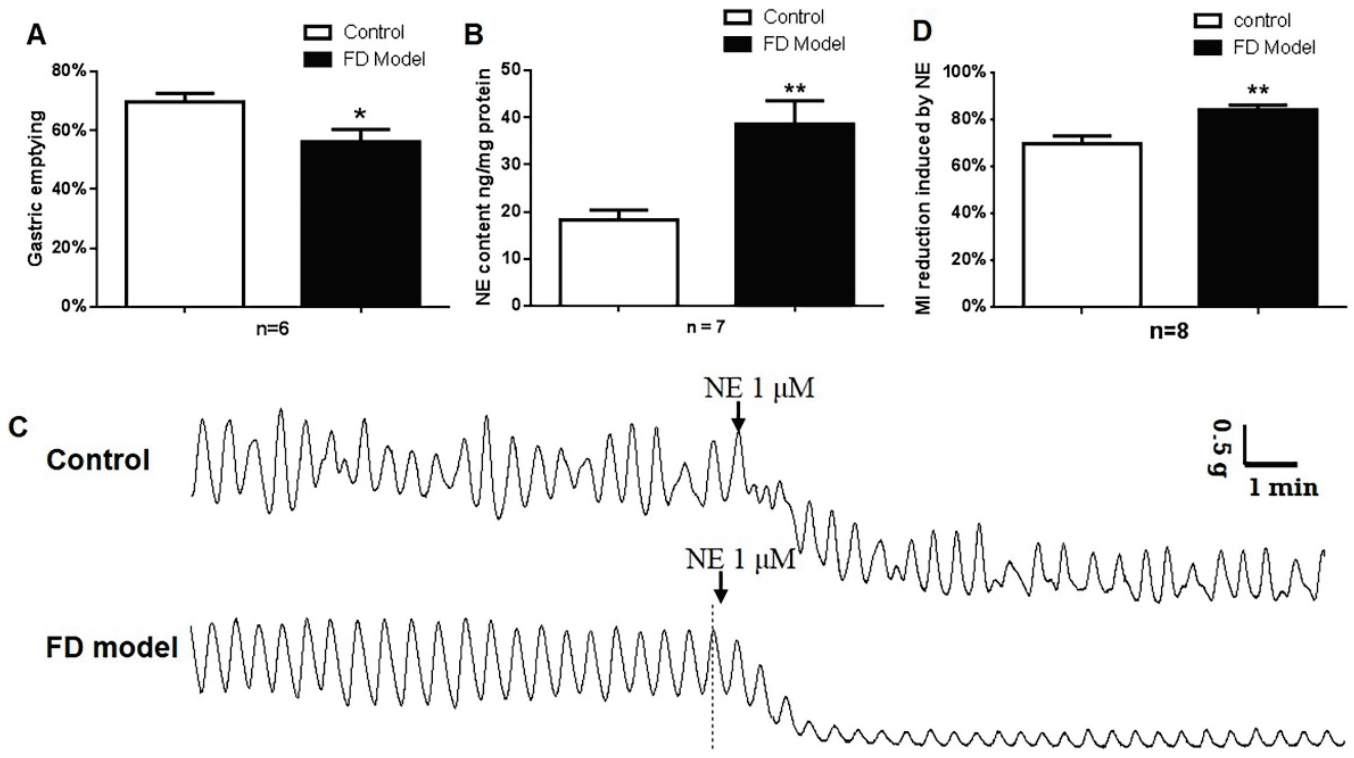

Fig. 1. NE-induced reduction of gastric motility in control and FD model rats. (A) Gastric emptying of solid food in FD model rats was reduced significantly $(n=6, P=0.036)$. (B) The NE content in the lamina muscularis of the stomach was increased in the FD model rats $(n=7, P=0.007)$. (C) Representative tracing of a strip in the gastric corpus of control and FD model rats. (D) The reduction rate of the motility index after NE $\left(10^{-6} \mathrm{M}\right)$ treatment compared with the basal condition was lower in FD model rats $(n=7, P=0.0221)$.

Expression of $\beta$-adrenoceptors and NET in gastric corpus

To further investigate the mechanism of hyperreactivity of gastric smooth muscle to NE in FD rats, the expression of $\beta$-adrenoceptors in the muscular layer of gastric corpus was measured in control and FD rats. Compared with that in the control group, the mRNA expression level of the $\beta_{1}$-adrenoceptor $(n=9$,
$P<0.05$ ) was increased by $34.46 \%$ in FD rats (Fig. 2A), and the protein level showed an upregulated tendency (Fig. 2B, C). The protein level of the $\beta_{2}$-adrenoceptor increased by $54.52 \%$ in FD rats, and the mRNA level showed an upregulated tendency. The $\beta_{3}$-adrenoceptor mRNA level was decreased while the protein level was increased (Fig. 2B, C).

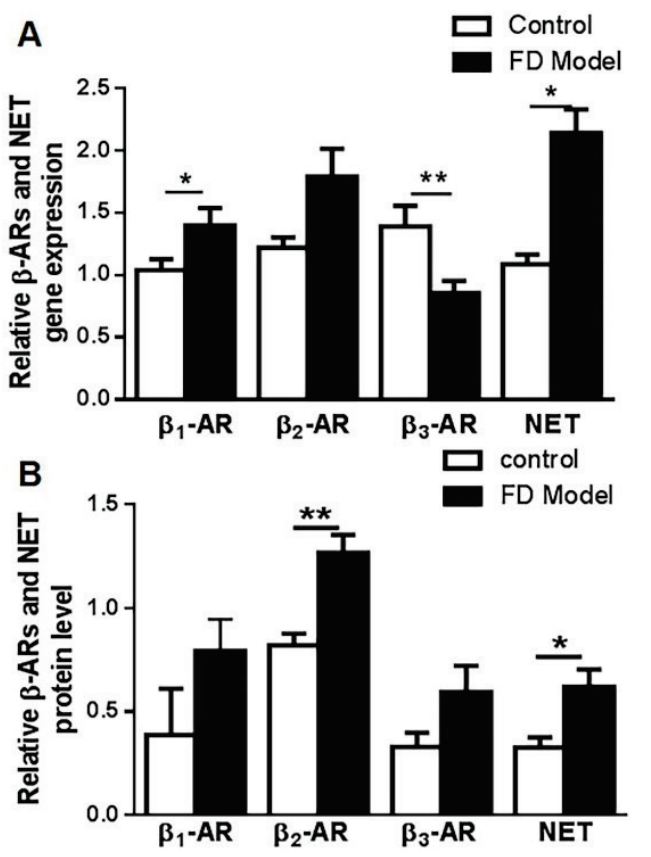

C

control FD model
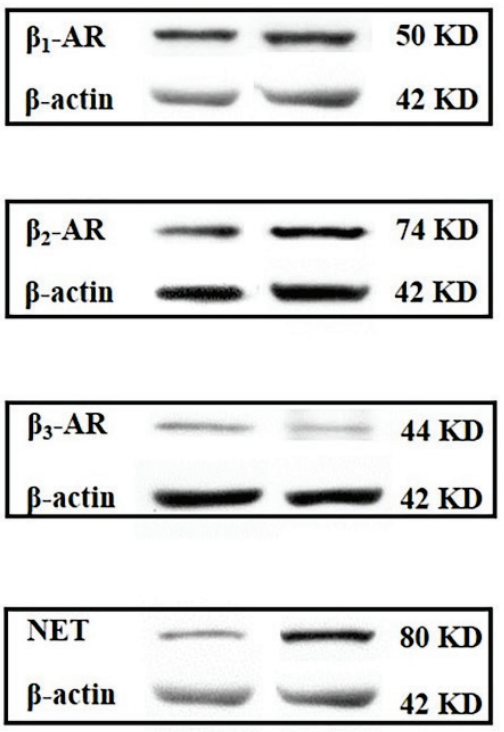

Fig. 2. Expression of the $\beta$-adrenoceptor in the muscular layer of the gastric corpus in control and FD rats. (A) The mRNA levels of $\beta$-adrenoceptors and NETs in the lamina muscularis of control and FD rats. (B, C) The protein levels of $\beta$-adrenoceptors and NETs in the muscular layer of control and FD rats. $\beta$-actin was the internal control for normalization. The data are expressed as the mean \pm SEM; ${ }^{*} P<0.05 ;{ }^{* *} P<0.01$. 
The norepinephrine transporter (NET) is mainly responsible for the reuptake of NE, which is important for maintaining synaptic homeostasis. Because NET is a hallmark protein of noradrenergic neurons (Fan et al. 2009), we examined its expression in the gastric corpus of control and FD rats. The NET mRNA level was increased by $96.87 \%(n=9, P<0.05)$, and the protein level was increased by $89.23 \%$ in FD rats compared with that in control rats (Fig. 2B, C). Our present results indicated that sympathetic regulation was enhanced in the gastric corpus of FD rats.
Distribution of $\beta$-adrenoceptors in the gastric corpus in rats

All three subtypes were observed in the gastric corpus of rats by immunofluorescence. As shown in Figure $3, \beta_{1}$-IR was mainly distributed in the mucous layer (Fig. 3A), while $\beta_{2}$ was abundantly distributed in the muscularis layer. In addition, $\beta_{2}$-IR was highly expressed in the myenteric plexus (Fig. 3B). $\beta_{3}$-IR were distributed in both mucous and muscularis layer (Fig. 3C). The present data provided morphological evidence for the above data.
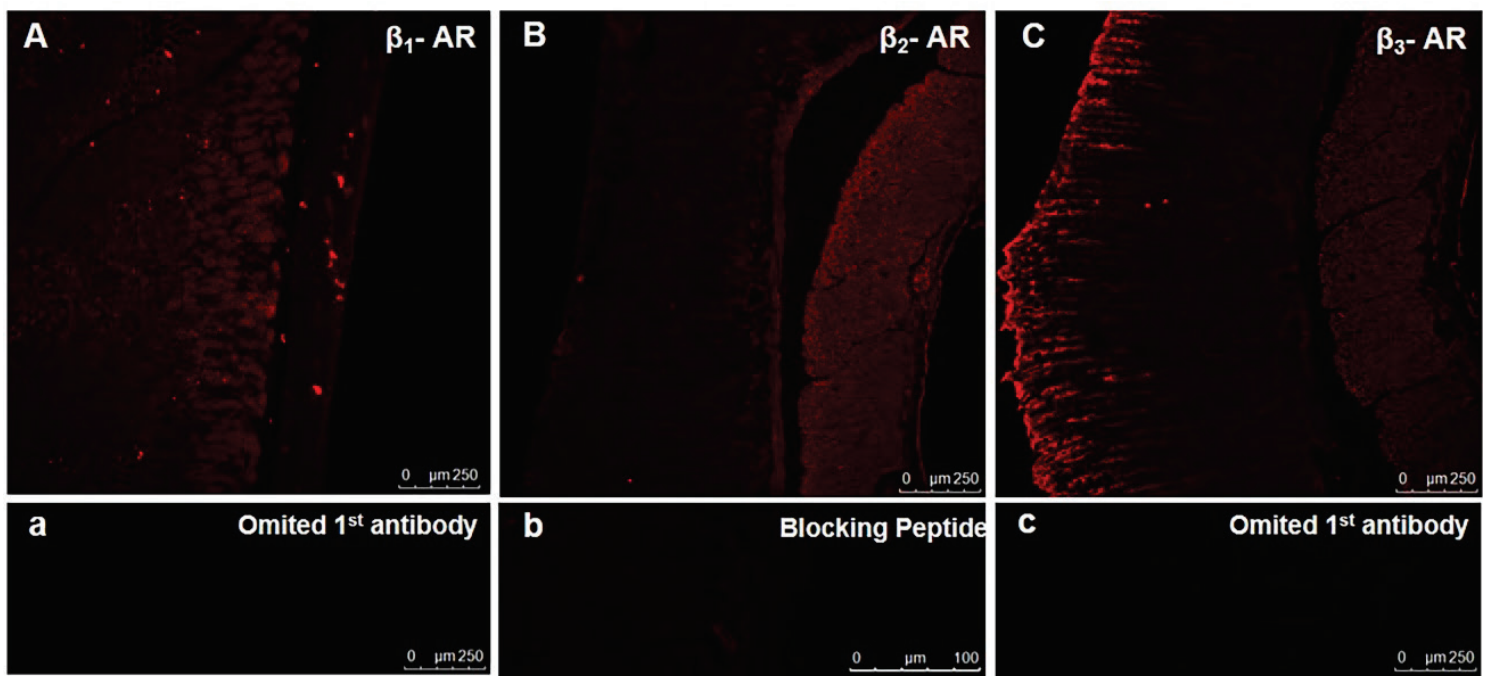

Fig. 3. Distribution of $\beta$-adrenoceptors ( $\beta$-ARs) in the full thickness of normal rats' gastric corpus. The distribution of $\beta_{1}-A R$ (A), $\beta_{2}-A R(B)$ and $\beta_{3}-A R(C)$ in the gastric corpus of normal rats. Control without primary antibodies of $\beta_{1}-A R(a), \beta_{3}-A R(c)$ and pretreatment with a blocking peptide of $\beta_{2}$-AR (b). Scale bar: $250 \mu \mathrm{m}$.

\section{Discussion}

Disturbed gastric motility has been reported in most FD patients. However, it is poorly managed in the clinic, and the underlying mechanisms are unclear. FD rats manifest delayed emptying. The present study demonstrated that enhanced adrenergic reactivity, elevated NE content, and upregulated expression of NET and of $\beta_{1}$ - and $\beta_{2}$-adrenoceptors were observed in the muscularis layer of the gastric corpus in FD rats. Our present results indicated that enhanced sympathetic regulation was involved in disordered gastric motility in FD rats.

Life stress contributes to symptom onset and exacerbation in the majority of patients with FD (Bennett et al. 1998). In our present study, tail-pinch stress was used to create a rat model of FD, which has been used in our previous study (Chang et al. 2017) as well as other studies (Wei et al. 2011). This method simulates the main etiology and symptoms of FD, as well as the pathological state of anxiety and stress in FD patients. It has been reported that tail-pinch stress enhances the release of catecholamines (NE and dopamine) in the locus coeruleus and NE release in the hippocampus (Kaehler et al. 2000, Rosario et al. 1999). The sympathetic division of the ANS is important in the control of GI function under both basal and stress conditions (McIntyre et al. 1992). However, no published paper has established the role of the sympathetic system in the regulation of GI motility in FD patients or animal models of FD. For the first time, our present study demonstrated that enhanced sympathetic regulation of gastric motility may be partly involved in the pathogenesis of FD. Our present results were, to some extent, consistent with the results of the abovementioned studies in brain (Kaehler et al. 2000, Rosario et al. 1999).

The sympathetic nervous system predominantly inhibits GI motility and plays a tonic inhibitory role on 
mucosal secretion (Browning et al. 2014). $\mathrm{NE}$ is a primary neurotransmitter of the sympathetic nervous system and can exert an inhibitory effect on gastric motility via $\beta$-adrenoceptors located on the smooth muscle (Song et al. 2014). It has been reported that selective agonists of $\alpha_{2}$-adrenoceptors can exert inhibitory effects on gastric motor activity in rats (Zadori et al. 2007). However, in our previous study, $\alpha$-adrenoceptors were not involved in the inhibitory effect of $\mathrm{NE}$ on gastric motility, as the specific antagonists did not block the effect induced by NE (Song et al. 2014). These inconsistent results might be related to the different experimental designs and techniques. Canciani et al. (2006) investigated the intragastric pressure by in vivo balloon measurement, whereas our studies were carried out on freshly isolated gastric muscle strips via an ex vivo force transducer. Moreover, the expression of $\alpha_{2}$-adrenoceptors has been reported to be widely distributed in the brain and myenteric plexus (Sjoholm et al. 1999), indicating that $\alpha_{2}$-adrenoceptors are mainly involved in the regulation of gastric motility via the neural pathway.

The endogenous NE in the gastric corpus was elevated in FD rats in our present study, which might be the consequence of stress conditions. Furthermore, exogenous NE induced more inhibition of gastric motility in FD rats, indicating hyperreactivity to NE in FD. Our present results might partly explain the mechanism of decreased gastric motility in patients with FD. The upregulated $\beta$-adrenoceptors might be an adapted response to the elevated endogenous NE, which is also related to the disordered gastric motility in FD. NET is a 12-transmembrane protein that is localized presynaptically on noradrenergic nerve terminals. The reuptake of NE is accomplished by the NETs located on the synapse, which is the main mechanism for the inactivation of released NE (Aggarwal et al. 2017). Sympathetic neurons are a predominant source of NETs, and their axons are projected into the gut; therefore, NETs play a strong role in determining the distribution of sympathetic nerves (Mayer et al. 2006). In our present study, the mRNA and protein levels of NETs in the gastric corpus were consistently upregulated in FD rats. We hypothesized that the elevated endogenous NE may lead to increased NE reuptake, which might be an adaptive alteration to maintain physiological NE concentrations in the stomach.

In conclusion, our present study showed that elevated gastric NE, hyperreactivity of gastric smooth muscle to $\mathrm{NE}$ and upregulated $\beta$-adrenoceptors might contribute to delayed gastric emptying observed in the rat model of FD. The present study provides new clues for the pathogenesis and therapeutic target of disordered gastric motility in FD.

\section{Conflict of Interest}

There is no conflict of interest.

\section{Acknowledgements}

This work was supported by the National Natural Science Foundation of China (Grant No. 81774215).

\section{References}

AGGARWAL S, MORTENSEN OV: Overview of monoamine transporters. Curr Protoc Pharmacol 79: 12.16.1-12.16.17, 2017. https://doi.org/10.1002/cpph.32

AZIZ I, PALSSON OS, TORNBLOM H, SPERBER AD, WHITEHEAD WE, SIMREN M: Epidemiology, clinical characteristics, and associations for symptom-based Rome IV functional dyspepsia in adults in the USA, Canada, and the UK: a cross-sectional population-based study. Lancet Gastroenterol Hepatol 3: 252-262, 2018. https://doi.org/10.1016/S2468-1253(18)30003-7

BENNETT EJ, TENNANT CC, PIESSE C, BADCOCK CA, KELLOW JE: Level of chronic life stress predicts clinical outcome in irritable bowel syndrome. Gut 43: 256-261, 1998. https://doi.org/10.1136/gut.43.2.256

BROWNING KN, TRAVAGLI RA: Central nervous system control of gastrointestinal motility and secretion and modulation of gastrointestinal functions. Compr Physiol 4: 1339-1368, 2014. https://doi.org/10.1002/cphy.c130055

CANCIANI L, GIARONI C, ZANETTI E, GIULIANI D, PISANI R, MORO E, TRINCHERA M, CREMA F, LECCHINI S, FRIGO G: Functional interaction between alpha2-adrenoceptors, mu- and kappa-opioid receptors in the guinea pig myenteric plexus: effect of chronic desipramine treatment. Eur J Pharmacol 553: 269-279, 2006. https://doi.org/10.1016/j.ejphar.2006.09.025 
CARBONE F, TACK J: Gastroduodenal mechanisms underlying functional gastric disorders. Dig Dis 32: 222-229, 2014. https://doi.org/10.1159/000357854

CHANG X, ZHAO L, WANG J, LU X, ZHANG S: Sini-san improves duodenal tight junction integrity in a rat model of functional dyspepsia. BMC Complement Altern Med 17: 432, 2017. https://doi.org/10.1186/s12906-017$\underline{1938-2}$

FAN Y, HUANG J, KIERANN, ZHU MY: Effects of transcription factors Phox2 on expression of norepinephrine transporter and dopamine beta-hydroxylase in SK-N-BE(2)C cells. J Neurochem 110: 1502-1513, 2009. https://doi.org/10.1111/j.1471-4159.2009.06260.x

KAEHLER ST, SINNER C, PHILIPPU A: Release of catecholamines in the locus coeruleus of freely moving and anaesthetized normotensive and spontaneously hypertensive rats: effects of cardiovascular changes and tail pinch. Naunyn Schmiedebergs Arch Pharmacol 361: 433-439, 2000. https://doi.org/10.1007/s002109900210

LACY BE, WEISER KT, KENNEDY AT, CROWELL MD, TALLEY NJ: Functional dyspepsia: the economic impact to patients. Aliment Pharmacol Ther 38: 170-177, 2013. https://doi.org/10.1111/apt.12355

MAYER AF, SCHROEDER C, HEUSSER K, TANK J, DIEDRICH A, SCHMIEDER RE, LUFT FC, JORDAN J: Influences of norepinephrine transporter function on the distribution of sympathetic activity in humans. Hypertension 48: 120-126, 2006. https://doi.org/10.1161/01.HYP.0000225424.13138.5d

MCINTYRE AS, THOMPSON DG: Review article: adrenergic control of motor and secretory function in the gastrointestinal tract. Aliment Pharmacol Ther 6: 125-142, 1992. https://doi.org/10.1111/j.13652036.1992.tb00257.x

PARK DI, RHEE PL, KIM YH, SUNG IK, SON HJ, KIM JJ, PAIK SW, RHEE JC, CHOI KW: Role of autonomic dysfunction in patients with functional dyspepsia. Dig Liver Dis 33: 464-471, 2001. https://doi.org/10.1016/S1590-8658(01)80023-2

ROSARIO LA, ABERCROMBIE ED: Individual differences in behavioral reactivity: correlation with stress-induced norepinephrine efflux in the hippocampus of Sprague-Dawley rats. Brain Res Bull 48: 595-602, 1999. https://doi.org/10.1016/S0361-9230(99)00040-4

SAHAN HE, YILDIRIM EA, SOYLU A, TABAKCI AS, CAKMAK S, ERKOC SN: Comparison of functional dyspepsia with organic dyspepsia in terms of attachment patterns. Compr Psychiatry 83: 12-18, 2018. https://doi.org/10.1016/j.comppsych.2018.02.007

SJOHOLM B, LAHDESMAKI J, PYYKKO K, HILLILA M, SCHEININ M: Non-adrenergic binding of $[3 \mathrm{H}]$ atipamezole in rat kidney--regional distribution and comparison to alpha2-adrenoceptors. Br J Pharmacol 128: 1215-1222, 1999. https://doi.org/10.1038/sj.bjp.0702917

SONG J, ZHENG L, ZHANG X, FENG X, FAN R, SUN L, HONG F, ZHANG Y, ZHU J: Upregulation of beta1-adrenoceptors is involved in the formation of gastric dysmotility in the 6-hydroxydopamine rat model of Parkinson's disease. Transl Res 164: 22-31, 2014. https://doi.org/10.1016/j.trs1.2014.01.001

STANGHELLINI V, TACK J: Gastroparesis: separate entity or just a part of dyspepsia? Gut 63: 1972-1978, 2014. https://doi.org/10.1136/gutjnl-2013-306084

TACK J, CAMILLERI M: New developments in the treatment of gastroparesis and functional dyspepsia. Curr Opin Pharmacol 43: 111-117, 2018. https://doi.org/10.1016/j.coph.2018.08.015

TALLEY NJ, FORD AC: Functional dyspepsia. N Engl J Med 373: 1853-1863, 2015. https://doi.org/10.1056/NEJMra1501505

TALLEY NJ, WEAVER AL, ZINSMEISTER AR: Impact of functional dyspepsia on quality of life. Dig Dis Sci 40: 584-589, 1995. https://doi.org/10.1007/BF02064375

TOMINAGA K, FUJIKAWA Y, TSUMOTO C, KADOUCHI K, TANAKA F, KAMATA N, YAMAGAMI H, TANIGAWA T, WATANABE T, FUJIWARA Y, ARAKAWA T: Disorder of autonomic nervous system and its vulnerability to external stimulation in functional dyspepsia. J Clin Biochem Nutr 58: 161-165, 2016. https://doi.org/10.3164/jcbn.15-140

WEI W, LI X, HAO J, ZHANG R, GUO J, ZONG Y, LU Y, QU S, TIAN J: Proteomic analysis of functional dyspepsia in stressed rats treated with traditional Chinese medicine "Wei Kangning". J Gastroenterol Hepatol 26: 1425-1433, 2011. https://doi.org/10.1111/j.1440-1746.2011.06566.x 
WINSTON JH, SARNA SK: Enhanced sympathetic nerve activity induced by neonatal colon inflammation induces gastric hypersensitivity and anxiety-like behavior in adult rats. Am J Physiol Gastrointest Liver Physiol 311: G32-G39, 2016. https://doi.org/10.1152/ajpgi.00067.2016

ZADORI ZS, SHUJAA N, FULOP K, DUNKEL P, GYIRES K: Pre- and postsynaptic mechanisms in the clonidineand oxymetazoline-induced inhibition of gastric motility in the rat. Neurochem Int 51: 297-305, 2007. https://doi.org/10.1016/j.neuint.2007.06.027

ZHANG X, LI Y, LIU C, FAN R, WANG P, ZHENG L, HONG F, FENG X, ZHANG Y, LI L, ZHU J: Alteration of enteric monoamines with monoamine receptors and colonic dysmotility in 6-hydroxydopamine-induced Parkinson's disease rats. Transl Res 166: 152-162, 2015a. https://doi.org/10.1016/j.trsl.2015.02.003

ZHANG X, LI Y, ZHANG X, DUAN Z, ZHU J: Regulation of transepithelial ion transport in the rat late distal colon by the sympathetic nervous system. Physiol Res 64: 103-110, 2015b. 